\title{
Evaluation of Analgesic and Anti-inflammatory Effects of a Poly-herbal Ayurvedic Formulation
}

\author{
Mohammad Jashim Uddin ${ }^{1}$, Md. Abdul Motaleb Bhuiyan, Kishor Mazumder ${ }^{1}$, \\ Mohammad Shohel $^{1}$, Md. Belayet Hossain ${ }^{2}$, Abu Asad chowdhury², Md. Abdul Mazid ${ }^{2}$ \\ ${ }^{1}$ Department of Pharmacy, University of Science and Technology Chittagong, Chittagong 4202, Bangladesh. \\ ${ }^{2}$ Department of Pharmaceutical Chemistry, Faculty of Pharmacy, University of Dhaka, Dhaka 1000, Bangladesh.
}

\begin{abstract}
A poly-herbal ayurvedic formulation containing Sida retusa (root), Withania somnifera, Frillaria roylei, and Paederia foetida (prasarini) is used in the treatment of inflammation and pain based on the long-term experience of the ayurvedic physicians, but no scientific study has been carried out so far. We have evaluated the analgesic and anti-inflammatory activities of the poly-herbal preparation using different animal models such as hot plate method for analgesic activity and anti-inflammatory activity by carrageenan-induced inflammation. Significant analgesic activity of the poly-herbal formulation was found after 2 hours as compared to the control. The product also showed sufficient anti-inflammatory activity while checked against carrageenan induced inflammation.
\end{abstract}

Key words: Poly-herbal, ayurvedic formulation, analgesic, anti-inflammatory.

\section{Introduction}

Poly-herbal ayurvedic medicines are prescribed for the treatment of various ailments including pain, inflammation, fever, etc for hundreds of years. However, most of them are used or prescribed usually based on the long-term experience of the indigenous or ayurvedic physicians, without enough scientific evidences. A polyherbal formulation (encoded as BLR), prescribed in the treatment of pain and inflammation associated with arthritis was selected for the evaluation of the claimed pharmacological actions. Each $5 \mathrm{ml}$ of the poly-herbal formulation, BLR contains Sida retusa (Linn.) Borssum root (Fam.- Malvaceae, Bengali name - Berela), 1.35 gm; Withania somnifera (Fam. - Solanaceae, Bengali name Ashwagandha or also called Indian ginseng), 1.35 gm; Fritillaria roylei (Fam. - Liliaceae, Beagali name Khirokakoli), 28.15 mg; and Paederia foetida (Fam. Rubiaceae, Bengali name - Prasarini), 14.08 mg.

Sida retusa is used in arthritis, asthma, cough, flatulence, colic, burning sensation, hemorrhoids, intermittent fever, etc and phytochemical studies on this plant revealed the presence of asperuloside, paederosodic acid, ceryl alcohol, stigmasterol, ursolic acid, carotene, vit $\mathrm{C}$, arginine, cystine, lysine, tyrosine, valine, epifridelonol, etc (Phawal, 2007). Fritillaria roylei possess peimine, peiminine, peimisine, peimiphine, peimidine, peimitidine, propeimin, sterol, etc and has been reported for antiasthmatic, antirheumatic, febrifuge, galactogogue, haemostatic, ophthalmic and oxytocic properties, etc (Chi, 1936; Wu, 1944; Jiang, 2001). Several studies over the past few years have looked into the role of Withania somnifera in having anti-inflammatory, anti-tumor, antistress, antioxidant, mind-boosting, immune-enhancing, and rejuvenating properties, etc (Marderosion, 2001; Singh, 1998; Asthana, 1989; Mirjalili, 2009; Ven, 2010; Yadav, 2010; Senthil, 2011; Singh, 2011). Paederia foetida (Prasaroni) is traditionally used in hemorrhoids, arthritis, urinary system diseases, inflammation, etc and phytochemical studies revealed the presence of essential oils, glucosides, quinines, alkaloids, etc (Nadkarni, 1954; Wang, 1994; De, 1994; Osman 2009).

Although, each of the plant is claimed traditionally to possess many ethnomedical values including analgesic and anti-inflammatory activities, and several investigations have been carried out on individual plant or plant parts to explore the values. However, no scientific evidence has been established so far to evaluate the antiinflammatory and analgesic effects of the poly-herbal formulation. Although it is of immense need to evaluate the poly-herbal formulation to evaluate its safety and efficacy, but until now little attention has been paid to evaluate the poly-herbal formulations prescribed for the patients. Therefore, the present study was carried out to investigate these pharmacological effects of BLR by using animal models.

Correspondence to: M.A. Mazid, E-mail: mazid_ma@hotmail.com, Fax: +880-2-8615583, Tel: +880-2-9661920, Ext. 8131 


\section{Materials and Methods}

Collection and preparation of the liquid formulation: Each component of the poly-herbal formulation, BLR was collected from a local company at Chittagong, Bangladesh and prepared according to the Ayurvedic formulary. Each $5 \mathrm{ml}$ of the poly-herbal preparation, BLR contains Sida retusa root $1.35 \mathrm{gm}$, Withania somnifera $1.35 \mathrm{gm}$, Fritillaria roylei $28.15 \mathrm{mg}$ and Paederia foetida 14.08 mg.

Experimental animal: Male and female Swiss albino mice weighing 20-40 gm were used in this experiment. The animals were provided with standard laboratory food and water ad libitum and maintained at natural day night cycle. Eight mice were taken in each group. All the animals were marked at the tail for later identification. For all the pharmacologic studies, BLR was administered orally at $20 \mathrm{ml} / \mathrm{kg}$ of body weight. For control group, equal number of mice was used that was administered with distilled water at the same volume of treated drug.

Analgesic activity by hot plate reaction time: The analgesic activity of the experimental drug was measured by Woolf and MacDonald's method with some modifications. In short, the laboratory hot plate (model no: DS-37, SOCREL) was maintained at a constant temperature of $55^{\circ} \pm 1^{\circ} \mathrm{C}$. Swiss albino mice were placed on the hot plate and the time until either licking or jumping occurs was recorded by a stop-watch. A cut off period of $30 \mathrm{sec}$ was maintained to avoid damage to the paw. The drugs or vehicle were administered orally and the reaction time was observed again at 1/2, 1, 2, 3, $4 \mathrm{~h}$ after drug administration. Aminopyrine at a dose of 50 $\mathrm{mg} / \mathrm{kg}$ body weight was used as positive control.

Anti-inflammatory activity test against carrageenan induced inflammation in the hind paw of rat: The plethysmometer (Model no: 7150,UGO Basile, Italy) was used for anti-inflammatory test (Amresha 2007; Gokhale
2002). At first, initial paw volume of each rat was taken and then BLR (Dose: $20 \mathrm{ml} / \mathrm{kg}$ ) was fed orally, while control, received the vehicle only. After $30 \mathrm{~min}$ of administration of the test drug, the rats were injected with $0.1 \mathrm{ml}$ of carrageenan $(1 \% \mathrm{w} / \mathrm{v}$ in water) into the subplantar area of right hind paw. The paw volumes were measured using plethysmometer. Phenylbutazone at a dose of $100 \mathrm{mg} / \mathrm{kg}$ body weight was used as positive control.

Statistical analysis: The observations are represented as Mean \pm S.E.M. The data were processed by one-way analysis of variance (ANOVA) followed by student t-test. $* P<0.05$ was considered significant.

\section{Results}

Analgesic activity: The analgesic activity of the polyherbal formulation, BLR was evaluated by hot plate method as described earlier. The reaction time until either licking or jumping of the mice was determined at different time intervals (1/2, 1, 2, 3, $4 \mathrm{hr})$ after administration of BLR at $20 \mathrm{ml} / \mathrm{kg}$ body weight and compared with control. The BLR showed significant increase in the reaction time at 2-, 3- and 4-hr when compared to the control (Table-1) indicating the low response to the hot environment. This suggests the analgesic activity of the test sample. The effects were also comparable with that of positive control aminopyrine.

Table 1. Tabular representation of hot plate test of BLR

\begin{tabular}{llll}
\hline Hour & Control $^{\mathrm{a}}$ & BLR $^{\mathrm{a}}$ & Aminopyrine $^{\mathrm{a}}$ \\
\hline $30 \mathrm{~min}$ & $12.66 \pm 0.08$ & $11.86 \pm 0.05$ & $14.86 \pm 0.03$ \\
$1^{\text {st }}$ hrs & $12.07 \pm 0.08$ & $14.10 \pm 0.07$ & $16.10^{*} \pm 0.06$ \\
$2^{\text {nd }} \mathrm{hrs}$ & $13.06 \pm 0.09$ & $18.14^{*} \pm 0.06$ & $21.14^{*} \pm 0.12$ \\
$3^{\text {rd }} \mathrm{hrs}$ & $13.10 \pm 0.06$ & $18.13^{*} \pm 0.08$ & $22.93^{*} \pm 0.07$ \\
$4^{\text {th }}$ hrs & $13.09 \pm 0.10$ & $20.13^{*} \pm 0.09$ & $23.74^{*} \pm 0.08$ \\
\hline
\end{tabular}

${ }^{\mathrm{a}}$ Each value is the Mean \pm S.E.M. for 6 rats, $* \mathrm{P}<0.01$ compared with control.

Table 2. Effect of poly-herbal formulation on carrageenan-induced hind paws edema

\begin{tabular}{lcccccc}
\hline Treatment & Dose & \multicolumn{4}{c}{ Edema volume $(\mathrm{ml})(\%$ inhibition $)$} \\
\cline { 3 - 6 } & & $0 \mathrm{~min}$ & $1^{\text {st }} \mathrm{hr}$ & $2^{\text {nd }} \mathrm{hr}$ & $3^{\text {rd }} \mathrm{hr}$ & $4^{\text {th }} \mathrm{hr}$ \\
\hline Control & Vehicle & $0.54 \pm 0.03$ & $0.73 \pm 0.02$ & $0.80 \pm 0.02$ & $1.16 \pm 0.02$ & $1.25 \pm 0.03$ \\
\hline BLR & $20 \mathrm{ml} / \mathrm{kg}$, & $0.53 \pm 0.05$ & $0.71 \pm 0.05$ & $0.52^{*} \pm 0.06$ & $0.63^{*} \pm 0.01$ & $0.66^{*} \pm 0.02$ \\
& oral & $(0)$ & $(2.7)$ & $(34.8)$ & $(45.2)$ & $(47.3)$ \\
\hline Phenylbutazone & 100, i.p. & $0.54 \pm 0.04$ & $0.59 \pm 0.04$ & $0.48^{*} \pm 0.01$ & $0.55^{*} \pm 0.01$ & $0.57^{*} \pm 0.02$ \\
& & $(0)$ & $(19.1)$ & $(40.0)$ & $(52.5)$ & $(54.4)$ \\
\hline
\end{tabular}

Each value is the Mean \pm S.E.M. for 6 rats, $* \mathrm{P}<0.05$ compared with control.

$\%$ Inhibition $=100(1-(a / b))$ where $a=$ mean paw volume of treated animals; $b=$ mean paw volume of control animals. 
Anti-inflammatory activity: The BLR was evaluated for anti-inflammatory activity in acute and chronic experimental rat models. The effect of poly-herbal preparation, BLR on carrageenan induced paw oedema in rats is shown in Table 2. The result obtained indicates BLR to have significant $(\mathrm{P}<0.01)$ anti-inflammatory activity in rats. The test sample at the test dose $20 \mathrm{ml} / \mathrm{kg}$ body weight reduced the oedema induced by carrageenan by $34.8 \%, 45.2 \%, 47.3 \%$ at 2-, 3- and $4-\mathrm{hr}$, respectively and was comparable with that of the standard, phenylbutazone.

\section{Discussion}

The results of the present study shows that BLR possesses significant analgesic and anti-inflammatory activities in all the tested experimental animals (Table 1 and Table 2). The data in the Table 1 showed that BLR possess significant analgesic activity at $3^{\text {rd }}$ and $4^{\text {th }}$ hrs as compared to the standard drug aminopyrine. The data also indicates that the poly-herbal formulation possesses central analgesic activity which was evaluated using hot plate method.

On the other hand, the data presented in Table 2 showed that BLR reduces edema volume by $45.2 \%$ at $3^{\text {rd }}$ hr and $47.3 \%$ by $4^{\text {th }} \mathrm{hr}$ and seemed to be significant as compared to phenylbutazone $\left(52.5 \%\right.$ at $3^{\text {rd }} \mathrm{hr}$ and $54.4 \%$ at $4^{\text {th }} \mathrm{hr}$ ). The inflammation induced by carrageenan is biphasic. The initial phase of the edema is due to the release of histamine and serotonin and the edema is maintained during the plateau phase by kinin like substance (Chauhan 1998) and the second accelerating phase of swelling due to the release of prostaglandin like substances (Salvemini et al., 1996). Hence, it is assumed that apart from inhibition of chemical mediators of inflammation, BLR may also modulate the pain response in the central nervous system.

\section{Conclusion}

Drugs which are in use presently for the management of pain and inflammatory conditions are either narcotics e.g. opioids or non-narcotics e.g. salicylates and corticosteroids e.g. hydrocortisone. All of these drugs possess well known side and toxic effects. Moreover, synthetic drugs are very expensive to develop, and whose cost of development ranges from 0.5 to 5 million dollars. On the contrary, many medicines of plant origin had been used since long time without any adverse effects. Exploring the healing power of plants is an ancient concept. For centuries people have been trying to alleviate and treat diseases with different plant extracts and formulations (Cowan, 1999. As a part of such continuous efforts, our results showed that the poly-herbal formulation containing Sida retusa, Withania somnifera, Frillaria roylei and Paederia foetida possesses potent analgesic and anti-inflammatory effects. Further evaluation is necessary to find out the exact mechanism of the observed actions.

\section{Acknowledgement}

Mohammad Jashim Uddin and Md. Abdul Motaleb Bhuiyan equally contributed in this research work.

\section{Reference}

Amresha, G., Singh, P.N. and Rao, C.V. 2007. Antinociceptive and antiarthritic activity of Cissampelos pareira roots. $J$. Ethnopharmacol. 111, 531-536.

Asthana, R. and Raina, M.K. 1989, Phamacology of Withania Somnifera (L.) Dunal-a review. Indian drug. 26, 199-205.

Chauhan, O., Godhwani, J. L., Khanna, N. K. and Pendse, V. K. 1998, Antiinflammatory activity of muktashukti bhasma. Indian J. Exp. Biol. 36, 985-989.

Chi Yuoh-Fong, Kao Y S. and Chang K.J. 1936. The Alkaloids of Fritillaria Roylei. Isolation of Peimine1, J. Am. Chem. Soc. 58 , 1306-1307.

Cowan, M. M. 1999. Plants products antimicrobial agents. Clin. Microbial. Rev.14, 564-584.

De, S., Ravishankar, B. and Bhavsar, G.C. 1994. Investigation of the anti-inflammatory effects of Paederia foetida. $J$. Ethnopharmacol. 43, 31-38.

Gokhale, A. B., Damre, A. S., Kulkarni, K. R. and Saraf, M. N. 2002. Preliminary evaluation of anti-inflammatory and antiarthritic activity of S. lappa, A. speciosa and A. aspera, Phytomedicine. 9, 433-437.

Jiang RW, Ma SS, But PP, Dong H, Mak TC. 2001. Sipeimine, a steroidal alkaloid from Fritillaria roylei Hooker. Acta Crystallogr. C. 57, 170-171.

Marderosion, A.D. 2001, The review of natural products, facts and comparisons; St. Lawis, MI, USA, pp. 630-632. 
Mirjalili, M.H., Moyano, E., Bonfill, M., Cusido, R.M. and Palazón, J. 2009. Steroidal lactones from Withania somnifera, an ancient plant for novel medicine. Molecules 14, 2373-2393.

Nadarani, K.M. 1954, India Materia Medica, popular book deport, Bombay, India, vol. I, P. 1137.

Osman, H., Rahim, A.A., Isa N.M. and Bakhir, N.M. 2009. Antioxidant activity and phenolic content of Paederia foetida and Syzygium aqueum. Molecules. 14, 970-978.

Phawal, K., Deshpenda Y.S.. and Purohit, A.P. 2007. Evaluation of in-vitro antioxidant activity of Sida rhombifolia (L.) and Sida retusa. J. Med. Food 10, 267-271.

Salvemini, D., Wang, Z.Q., Bourdon, D.M., Stern. M.K., Currie, M.G. and Manning, P.T. 1996. Evidence of peroxynitrite involvement in the carrageenaninduced rat paw edema. Eur. J. Pharmacol. 303, 217-224.

Scartezzini, P. and Speroni, E. 2000, Review on some plants of Indian traditional medicine with antioxidant activity". $J$. Ethnopharma. 71, 23-43.

Senthil, K.M, Vinoth K.D., Saravana K.A, Aslam, A, and Shajahan, A. 2011, The phytochemical constituents of Withania somnifera and Withania obtusifolia by GCMS analysis, Intl. J. Pharmacog. Phytochem. Res. 3, 31-34.
Singh, S. and Kumar, S. 1998, Withania somnifera: The Indian Ginseng Ashwagandha; Central Institute of Medicinal and Aromatic Plants: Luchnow, India.

Singh, G. and Kumar, P. 2011. Evaluation of antimicrobial efficacy of flavonoids of Withania somnifera L. Indian $J$ Pharm Sci. 73, 473-478.

Ven Murthy, M. R.; Ranjekar, P. K.; Ramassamy, C.; Deshpande, M. 2010, Scientific basis for the use of Indian ayurvedic medicinal plants in the treatment of neurodegenerative disorders: Ashwagandha". Central Nervous System Agents in Medicinal Chemistry. 10, 238246.

Wang K.C. and Tan G.L. 1994. Steam volatile constituents of the arial parts of Paederia foetida L., Flavour Frag. J. 23, 2528.

Wheeler-Aceto, H. and Cowan, A. 1991. Neurogenic and tissue mediated components of formalin-induced edema: evidence for supraspinal regulation, Agents Action. 34, 264-269.

Wu Yun-Hsi. 1944. The constituents of Fritillaria roylei. J. Am. Chem. Soc. 66, 1778-1780.

Yadav B, Bajaj A, Saxena M, Saxena AK. 2010. In vitro anticancer activity of the root, stem and leaves of Withania somnifera against various human cancer cell lines. Indian $J$. Pharm. Sci. 72, 659-63. 